\title{
RTO Governance Structures Can Affect Capacity Market Outcomes
}

\author{
Seth Blumsack \\ Penn State University and Santa Fe Institute \\ blumsack@psu.edu
}

\author{
Kyungjin Yoo \\ Penn State University \\ kxy151@psu.edu
}

\begin{abstract}
Regional Transmission Organizations (RTOs), which coordinate delivery for over two-thirds of the electricity consumed in the U.S., are required by the FERC to employ stakeholder-driven mechanisms to establish market and operational rules. These "governance structures" set up a quasi-political process for determining which market rules are adopted and which are not. This study shows how governance systems are not simply administrative constructs but have real impacts - the details of how the market rules are made will ultimately affect market outcomes. Using the capacity market in the PJM Interconnection as a case study, we model the preferences of individual stakeholders over different capacity market designs, under different decision rules for which capacity market design is implemented. We compare capacity market design choices under PJM's current decision system, which requires a super-majority in a sector-weighted voting context to implement a new market rule, with the decision systems used in the New York ISO and also under systems of preferential voting. This voting model is integrated with a model of capacity market clearing which allows us to demonstrate how different decision systems matter in terms of installed capacity and capacity market outcomes.
\end{abstract}

\section{Introduction}

This study aims to show how the governance of regional transmission organizations (RTOs) is not just an administrative system but has a measurable impact on the electricity market. Our definition of "governance" primarily includes the administrative processes that each RTO has for establishing market and operational rules. The Federal Energy Regulatory Commission (FERC) requires RTOs to include some level of stakeholder engagement in establishing market and operational rules, but the mechanisms for stakeholder engagement vary widely by RTO [1]. The RTOs serving New England, New York and the MidAtlantic region confer substantial influence on stakeholders, who vote on whether specific rule changes should be filed with FERC. Other RTOs use stakeholders in a more advisory capacity. The definition of a "stakeholder" varies between RTOs - in the context of this paper (as in [2-4]) market participants are considered stakeholders, but other interested parties such as environmental groups and state regulators are not considered stakeholders. We explore different governance systems, especially voting rules, and show how different voting rules change market outcomes which can be presented in dollar terms.

The potential connection between RTO governance and market performance was first raised by Dworkin and Goldwasser [5] but has received more attention in the past few years [6-9]. We add to this growing literature on RTO governance by providing more direct and quantitative evidence of a relationship between RTO governance and market outcomes. As a specific case study, we explore different decision mechanisms that could be applied to the PJM voting system and show how these differences could change market outcomes in PJM's capacity market.

Previous work focusing on decision mechanisms in the PJM stakeholder process [2-4] showed that under the current voting system in PJM (which requires a supermajority in the context of sector-weighted voting, as described further in Section 2), stakeholders in PJM would have great deal of difficulty passing any proposal for capacity market reform. A strong coalition of endusers could prevent the passage of any market rule change that would tend to increase capacity prices. Existing analyses have also found that a small number of swing voters preventing passage of market rule changes that would tend to decrease capacity prices.

Results from prior work raise the question of the importance of the specific voting structure in which market rule proposals pass or fail. In addressing this question, we focus on two mechanisms for changing RTO decision systems: elimination of the supermajority requirement for voting and the use of preferential voting in which voters rank options in an order of their preference. Our approach builds a joint model of the stakeholder process by which the capacity market rules are established that is integrated with a model of capacity market clearing. We use this model to simulate voting outcomes under different decision systems, and 
then use the capacity market model to estimate the market implications of those systems.

The modeling approach described and implemented in this paper is able to connect the process of making decisions on market rules with outcomes in those markets. The importance of this has been suggested in the existing literature on RTO governance [2-5] but has not previously been implemented. This work also adds to the literature on interactions between individual and group preferences and outcomes in the power grid and electricity markets [10]. Our approach involves four steps.

1. Develop a candidate set of market rule revisions.

2. Model preferences of RTO stakeholders over these candidate market revisions. In this paper we use the method from [4], with a modification to handle cases where preferences may be ambiguous.

3. Model the voting outcome under different decision systems to determine which market rule is adopted.

4. Model the implementation of the adopted market rule and compare those modeled outcomes to actual outcomes (if historical data is available) or outcomes that would have prevailed under a different market rule.

We illustrate this approach using PJM's stakeholder process and capacity market. We model the preferences of each stakeholder in PJM over different parameters of the Variable Resource Requirement (VRR) curve, which is used as the demand curve in capacity market clearing. An actual set of proposed VRR curve reforms from 2011 is used as our set of candidate market rules. Based on these preferences, we model the prevailing VRR curve under different voting passage thresholds than PJM currently uses, and also under three different preferential voting models. In the case of the PJM capacity market, we find that either lowering the voting passage threshold or the use of a preferential voting mechanism enhances the political power of end-use customers in PJM and would lead to capacity market rules that would lower prices but also lower the level of installed capacity. The magnitude of the market impact of these different voting rules is highly sensitive to several market parameters, but the voting mechanism itself clearly has an impact.

In section 2, we explain the current voting rules of PJM and introduce alternative voting rules that we consider in this study. Section 3 shows how we modeled supply and demand curve in the capacity market to connect voting outcomes and market outcomes. Section 4 illustrates how we identified preference order and describes simulation results of expected voting outcome (and so the market outcome) under different voting rules. Section 5 offers some concluding thoughts and directions for future research.

\section{Modeling RTO Decision Systems}

This section introduces the different voting rules considered in this paper, as follows:

- PJM's current voting system, which uses sector weighted voting with a supermajority required for passage of a rule change;

- The voting system used in the New York ISO, which is similar to PJM but with different sector weights and a different passage threshold;

- Three preferential voting procedures: Instant Runoff Voting, Coombs Rule and Borda Count.

Preferential voting systems all require voters to express preferences over different alternatives, rather than asking them to choose one alternative. While there are drawbacks [11-13], proponents of the preferential voting system argue that it is less vulnerable to strategic voting, and it ensures winners to get majority when there are more than two alternatives [14-16]. Given the difficulties in passing capacity market reforms in PJM through its existing stakeholder process, preferential voting models are of particular interest.

\subsection{PJM's Voting Rule}

This section contains an abbreviated description of stakeholder voting in PJM; for a more detailed description, [2] or [4]. Each stakeholder in PJM must assign itself to one of five industry sectors: Generation Owners (GO), Transmission Owners (TO), Electric Distributors (ED), End-Use Customers (EUC), and Other Suppliers (OS). Compared to the other sectors that have reasonably intuitive definitions, the OS sector is very heterogeneous, including Curtailment Service Providers (or demand response aggregators), Muni/coop utilities, and Financial market players such as hedge funds. Figure 1 shows shares of sectors among 530 voting members in the PJM as of February 2019.

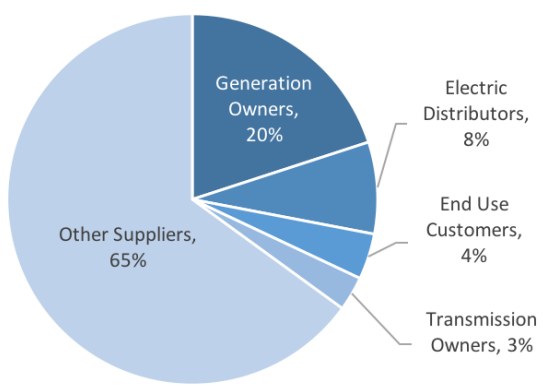

\section{Figure 1: PJM stakeholders by sector}

Each stakeholder can cast one vote per proposed alternative - yes, no, or abstain - and a proposed 
alternative is adopted if it receives two-thirds majority votes. PJM implements sector-weighted voting that gives equal weight to all five sectors. As a result, each sector gets $20 \%$ of the total voting score, and each sector's voting score represents a share of favoring votes of that sector excluding abstention votes. In other words, individual voters within the same sector share the one score and are inversely weighted by the number of voters of its sector. If the total voting score, or the sum of those score contributions, exceeds the threshold, then a voting issue would pass. The final voting score $\mathrm{V}$ is defined as:

$$
\boldsymbol{V}=\sum_{k} \sum_{i=1}^{\left(n_{k}-a_{k}\right)} w_{j k}=\sum_{k} \sum_{i=1}^{\left(n_{k}-a_{k}\right)} \frac{\delta_{i k}}{n_{k}-a_{k}}
$$

In (1), $\delta_{i k}$ is an indicator variable equal to one if a voter $i$ in sector k votes yes and zero if the voter votes no. $n_{k}$ is the total number of voters in sector $\mathrm{k}$, and $a_{k}$ is the number of abstention votes in sector $\mathrm{k}$. A voting item passes if its final voting score $V$ is greater than 3.335 . This implies that any two sectors could jointly prevent passage regardless of the number of voters in those sectors or the votes in other sectors.

Prior work [2-4] describes how this voting system has contributed to difficulties in capacity market reform in PJM. These difficulties are illustrated in Table 1, which shows the calculation of the voting score $V$ for six different VRR curve proposals considered in 2011. All six failed (including the option to make no changes to the VRR curve). The proposals themselves are shown visually in Figure 2. As [2,4] describe, those proposals that would have increased capacity prices (Packages 1, 10 and 11 in Figure 1) were defeated by the strong enduser coalition. Those proposals that would have decreased capacity prices (Packages 12 and 13) failed because of the actions of a small number of swing voters. After the voting process could not produce a passable reform to the VRR curve, PJM filed its preferred option (Package 1 in Figure 2) with FERC. Other things equal, Package 1 would have produced the largest increase in capacity prices relative to the status quo.

Table 1: Capacity market voting outcomes (Blumsack and Yoo, 2017)

\begin{tabular}{|l|l|l|l|l|l|l|}
\hline & Status Quo & Package 1 & Package 10 & Package 11 & Package 12 & Package 13 \\
\hline $\begin{array}{l}\text { Transmission } \\
\text { Owner }\end{array}$ & 0.083 & 0.8 & 0.75 & 0.167 & 0.167 & 0.333 \\
\hline $\begin{array}{l}\text { Generation } \\
\text { Owner }\end{array}$ & 0.071 & 0.833 & 0.714 & 0.077 & 0.231 & 0.267 \\
\hline $\begin{array}{l}\text { End Use } \\
\text { Customer }\end{array}$ & 0.083 & 0 & 0 & 0.909 & 1 & 1 \\
\hline $\begin{array}{l}\text { Electric } \\
\text { Distributor }\end{array}$ & 0.043 & 0 & 0 & 0.913 & 0.913 & 1 \\
\hline Other Supplier & 0.056 & 0.667 & 0.323 & 0.235 & 0.25 & 0.513 \\
\hline $\begin{array}{l}\text { Voting Score and } \\
\text { Result }\end{array}$ & 0.336 & 2.3 & 1.787 & 2.301 & 2.561 & 3.113 \\
\cline { 2 - 7 } & Failed & Failed & Failed & Failed & Failed & Failed \\
\hline
\end{tabular}

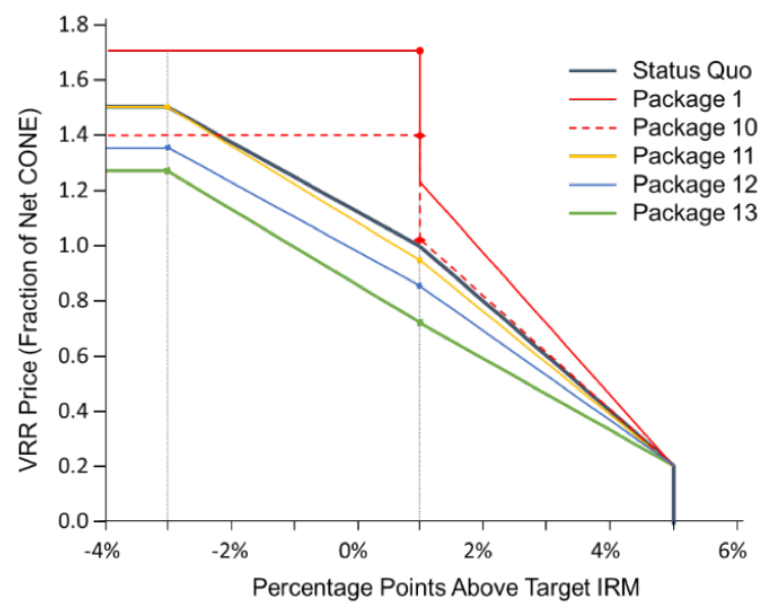

Figure 2: VRR proposals considered by PJM stakeholders. Source: Author calculations based on [17].

\subsection{The New York ISO Voting Rule}

Similar to PJM, voters in NYISO also have the same option per proposed voting issue - yes, no and abstain. There are, however, a few differences in terms of sector composition and sector weight as shown in Table 2. The most significant differences for our analysis are that the sectors are not equally weighted in NYISO (recall that each sector in PJM gets a 20\% weight), and the passage threshold is $58 \%$, which is lower than the $66.67 \%$ threshold in PJM.

Table 2: Voting structures in PJM and NYISO

\begin{tabular}{|l|l|l|l|l|}
\hline & \multicolumn{2}{|l|}{ PJM } & \multicolumn{2}{|l|}{ NYISO } \\
\hline Passage threshold & $66.67 \%$ & $58 \%$ & \\
\hline \multirow{4}{*}{$\begin{array}{l}\text { Sector and } \\
\text { sector weight }\end{array}$} & Generation owners & $20 \%$ & Generation owners & $21.5 \%$ \\
\cline { 2 - 5 } & Other suppliers & $20 \%$ & Other suppliers & $21.5 \%$ \\
\cline { 2 - 5 } & Transmission owners & $20 \%$ & Transmission owners & $20 \%$ \\
\cline { 2 - 5 } & End-Use Consumers & $20 \%$ & End-Use Consumers & $20 \%$ \\
\cline { 2 - 5 } & Electric Distributor & $20 \%$ & Public Power & $17 \%$ \\
\hline
\end{tabular}

Another difference is that NYISO has a Public Power sector and not an Electric Distributor sector as does PJM. There is, however, substantial overlap between the two sectors in terms of the kinds of companies falling under each. Our analysis here will thus treat them as equivalent (in other words, we assume that a firm in the Electric Distributor sector would be placed in the Public Power sector if that firm were located in New York).

\subsection{Preference Voting Rules}

In addition to the sector-weighted voting rules used by PJM and NYISO, we also model capacity market 
outcomes under three preference voting models: Instant runoff voting, the Coombs rule and the Borda count.

Instant runoff voting (IRV) is a preferential voting procedure with elimination. Voters in IRV rank all alternatives based on their preference. In the initial round, the first choices are counted and the winner is the alternative that gets first-place votes greater than or equal to a threshold. If no alternative surpasses the threshold, then the candidate with the fewest number of first-place votes is eliminated. Those voters whose first choice was eliminate see their votes distributed among other alternatives based on their second-place vote. This process of elimination continues until one alternative surpasses the threshold. Although IRV is often criticized for perplexity - it asks voters to specify their full preference over all alternatives which requires deeper understandings and thus more time [18], the proponents of IRV claim that IRV is comparatively resistant to strategic voting among preferential voting, increases probability for minority representation, and reduces cost in case of multiple runoffs are required [19-21].

The Coombs rule is similar to IRV. It requires voters to rank all alternatives and the procedure of elimination and transfer of votes continues until a winner is elected. The difference from IRV is the elimination rule - when there is no winner, the Coombs rule eliminates the alternative that receives the largest number of last-place votes.

The Borda count [22] is a voting procedure that has been considered extensively in the political science literature (the literature on this is large, but $[23,24]$ are examples). Similar to the IRV and the Coombs rule, voters under the Borda count are required to rank alternatives in a preference order. If the number of alternatives is $n$, the procedure assigns a score of $(n-1)$ to the first-place alternative, a score of $(n-2)$ to the second-place alternative, and so forth. The lowestranked alternative receives a score of zero. After combining scores from all voters, the alternative with the highest total score wins.

\section{Modeling Capacity Markets}

\subsection{Construction of the capacity market simulation model}

Section 2.1 described the failure of stakeholders in PJM to approve (by vote) any reforms to the VRR curve used in PJM's capacity market. The candidate VRR curves are shown in Figure 2, and our voting model will determine which of the VRR curves (if any) is ultimately adopted. This chosen VRR curve will serve as our capacity demand curve for capacity market simulations under alternative stakeholder voting structures.
PJM does not publish detailed data on the shape of the capacity offer curve. To estimate this curve, we employ data from the sensitivity analysis that was conducted by PJM [25] and from the analysis report of the market monitor of PJM [26] covering the capacity market for delivery in $2015 / 2016$. These sensitivity analyses provide information on what the capacity market clearing price and quantity would have been under different scenarios (e.g., more or less supply offered). For the purposes of this analysis, we do not consider special products in our capacity supply model, such as Extended Summer Demand Response. We also do not model zonal capacity price separation, which often occurs in PJM. Our estimated supply curve is shown in Figure 3.

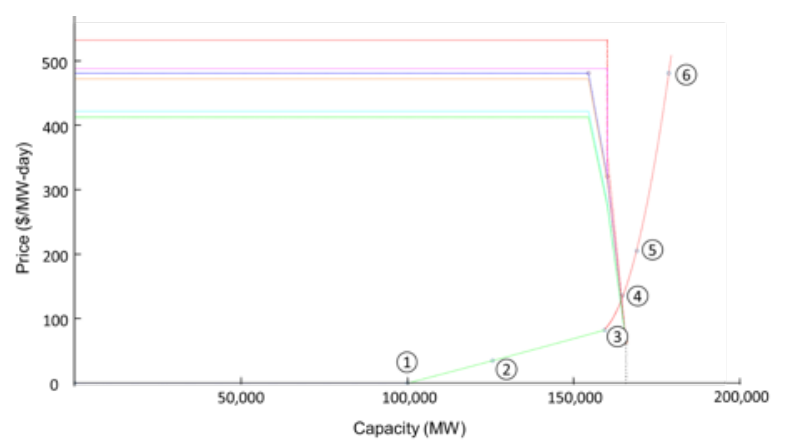

Figure 3: Simulated PJM capacity offer curve. The candidate VRR curves are also shown.

We use the results of two scenarios from PJM's analysis: the first scenario assumes the annual supply increases by 6,000 MW from the bottom of the supply curve, shifting the supply curve to the right; the second scenario assume the supply decreases by the same amount, shifting the supply curve to the left. Information from this sensitivity analysis give us three actual data points of the original supply curve: the actual market clearing point (point 4 in Figure 3), the first scenario's market clearing price at the clearing capacity of the base scenario minus 6,000 MW (point 3 in Figure 3 ), and the second scenario's market clearing price at the clearing capacity of the base scenario plus 6,000 MW (point 5 in Figure 3).

We also used two pieces of information from the market monitor report [26] to build our capacity offer curve. According to the report, $77 \%$ of the cleared capacity offered at or below $\$ 35 / \mathrm{MW}$-day. Assuming that the most expensive unit of the $77 \%$ offered at $\$ 35 / \mathrm{MW}$-day, the first data point is set at $\$ 35 / \mathrm{MW}$-day and $77 \%$ of the cleared capacity (point 3 in figure 3 ). The second data point is based on the assumption that the last (or the most expensive) unit of the cleared capacity offered at the price cap (point 6 in Figure 3). The end point of the flat portion (point 1 in Figure 3 ) is 
arbitrarily set, since in the context of this analysis it does not affect the clearing price result. Based on the five identified points, we construct the capacity offer curve as a piecewise function. The first segment assumes an offer price of zero (this is a strong assumption but does not affect our results). The second segment is a linear function connecting the end of the flat portion, $\$ 35 / \mathrm{MW}$-day offer point (point 2), and then to the first scenario point (point 3 ). The third segment is a quadratic function connecting the two scenario data points (points 3 and 5), the actual market clearing point (point 4), and the price cap point (point 6).

\subsection{Sensitivity of capacity market outcomes to the chosen VRR curve}

The capacity market model described in Section 3.1 allows for a comparative statics analysis to simulate different market clearing outcomes based on the chosen VRR curve. These simulated outcomes are shown in Table 3 and Figure 4.

Table 3: Modeled capacity market outcomes under different VRR curves

\begin{tabular}{|l|l|l|l|l|l|}
\hline $\begin{array}{l}\text { VRR Curve } \\
\text { (Ref. Fig. 2) }\end{array}$ & $\begin{array}{l}\text { Clearing Price } \\
\text { (\$/MW-day, } \\
\text { UCAP) }\end{array}$ & $\begin{array}{l}\text { Clearing } \\
\text { Quantity } \\
\text { (MW, UCAP) }\end{array}$ & $\begin{array}{l}\text { Total market } \\
\text { payment } \\
\text { (\$/day) }\end{array}$ & $\begin{array}{l}\% \text { change in } \\
\text { Price } \\
\text { compared to } \\
\text { Status quo }\end{array}$ & $\begin{array}{l}\% \text { change in } \\
\text { Quantity } \\
\text { compared to } \\
\text { Status quo }\end{array}$ \\
\hline Status Quo & 128.90 & 164,340 & $21,183,426$ & & \\
\hline Package 1 & 130.64 & 164,470 & $21,486,361$ & $1.35 \%$ & $0.08 \%$ \\
\hline Package 10 & 129.16 & 164,360 & $21,228,738$ & $0.20 \%$ & $0.01 \%$ \\
\hline Package 11 & 128.54 & 164,310 & $21,120,407$ & $-0.28 \%$ & $-0.02 \%$ \\
\hline Package 12 & 126.42 & 164,140 & $20,750,579$ & $-1.92 \%$ & $-0.12 \%$ \\
\hline Package 13 & 125.93 & 164,110 & $20,666,372$ & $-2.30 \%$ & $-0.14 \%$ \\
\hline
\end{tabular}

Of the VRR curves considered by stakeholders in PJM, Packages 1 and 10 would have generated higher clearing prices, other things being equal $(1.11 \%$ higher and $0.08 \%$ higher than the status quo). The remaining proposals (Packages 11, 12 and 13) would have lowered clearing prices relative to the status quo, other things being equal $(0.28 \%$ to $2.3 \%$ lower than the status quo). Based on our estimated supply curve, the difference between Packages 1 and 13 would have amounted to $\$ 256$ million in capacity revenue for a single delivery year, and would have changed the clearing quantity by $1 \%$, relative to the target installed capacity margin. These outcomes will be sensitive to the shape of the capacity offer curve around the market clearing point, which we discuss further in Section 4.

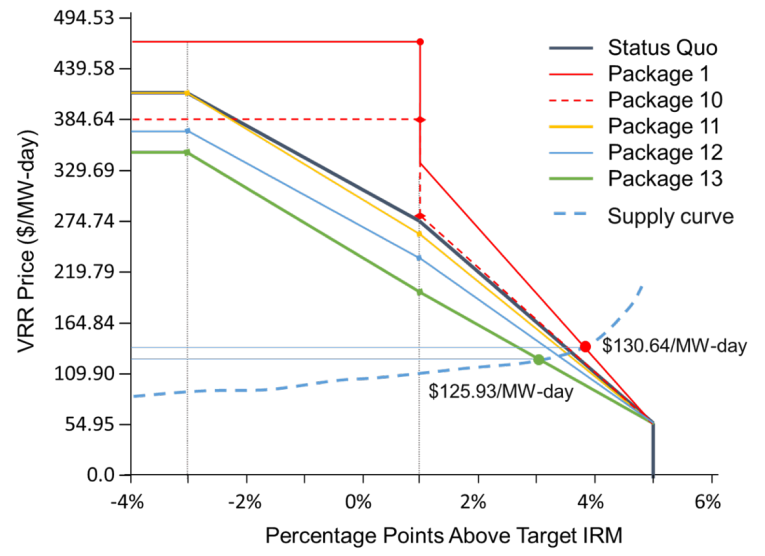

Figure 3: Illustrating the sensitivity of capacity market outcomes to the chosen VRR curve.

\section{The Impact of Voting Rules on Capacity Market Outcomes}

This section describes how the application of different voting rules in PJM (as described in Section 2) affect the choice of VRR parameters and thus capacity market outcomes. We state at the outset that an important assumption made throughout our analysis is that the stakeholder's voting behavior does not change when voting rule changes and modeling voting behavior under different voting rules remains as future work. While lowering the passage threshold (as in NYISO) is relatively clear in application, modeling preferential voting requires some care. Preferential voting requires voters to specify their full preference order without omitting any proposed alternatives. In the historical data on VRR curve votes in PJM in 2011, however, there are a considerable number of abstentions. This means that some stakeholders in PJM votes yes or no on some of the VRR curve alternatives but not others. Where voter preferences are not clear, we use a Monte Carlo approach to generate simulated voting outcomes. This allows us to examine whether outcomes under different voting systems are robust to uncertainty over voter preferences.

\subsection{Modeling voter preferences}

Based on prior work $[2,4]$ we develop relative preference orders over the VRR curve parameter packages (Figure 2) based on the votes of actual stakeholders in 2011, which we obtained from PJM [27]. This data set also contains information on individual stakeholders (including their industry sector, line of business and asset holdings) that we can use to develop a preference order where the voting record may 
be ambiguous. Stakeholders that we identify as consumers are assumed to prefer lower capacity clearing prices over higher prices. Their preference would be in the following order: package 13 (being the favorite for setting the lowest clearing price), package 12, package 11 , status quo, package 10 , and package 1 (being the least favorite for setting the highest clearing price). Stakeholders that we identify as suppliers would have the opposite preference order. Following this intuitive preference order, we assign number one to the favorite proposal (package 13 for the consumers and package 1 for the suppliers) and six to the least favorite (package 1 for the consumers and package 13 for the suppliers) by preference types.

As in [2] and [4] the preference modeling approach that we employ does have some limitations and some strong underlying assumptions. In particular, we assume that each voter will develop a preference ordering based only on its own payoffs under each capacity market proposal. We do not consider the potential for preference ordering to be influenced by coalition formation [28-30], nor do we consider any dynamic or game-theoretic dimensions of these preference orderings. These assumptions are fairly strong and limiting, but represent clear opportunities for further development of these kinds of voting models and implications of RTO governance structures.

We next categorize three preference types that we are able to divine from the historical voting data: Clear preferences that is consistent with our "consumer" or "supplier" stakeholder model; Abstention for those stakeholders with two or more abstentions in the voting data that makes their preference somewhat ambiguous; and Inconsistent preferences that contains mixed signals. These "inconsistent" stakeholders voted yes to both increasing and decreasing clearing price proposals, or there are too many abstention votes to identify their preference order.

For the clear preference type, there are two groups of preference order as described in the previous paragraph - the consumer group of 48 voters and the supplier group of 36 voters. The abstentions preference type also has the consumer and the supplier groups. We assign the values in the same way as we did for the clear preference type but only to proposals that voters specified their preference and leave blanks for proposals that received abstain vote. For example, two stakeholders in our data set voted yes to package 1 and abstained for all the other proposals. In this case, we assume that the stakeholder's most preferred option is package 1 for its preference order and leave blank for the others. Lastly, for the inconsistent preference type, we assume that they have random preferences and leave their preference order entirely blank.
Overall, there are 85 stakeholders in our data set whose preferences we categorize as clear, 11 stakeholders in our data set whose preferences we categorize as abstainers and 12 stakeholders whose preferences we describe as inconsistent.

Blank votes for the abstention and inconsistent groups are filled in using a Monte Carlo approach. Stakeholders in the inconsistent group have random preference orders generated. To generate a complete preference order for stakeholders in the abstention group, we first generate a preference ordering among the yes and no votes, and then randomly complete the preference order.

Table 4: Examples of modeling ambiguity in stakeholder preferences

(a)
\begin{tabular}{|l|l|l|}
\hline $\begin{array}{l}\text { VRR Curve } \\
\text { (Ref. Fig. 2) }\end{array}$ & $\begin{array}{l}\text { Actual } \\
\text { Vote }\end{array}$ & $\begin{array}{l}\text { Preference } \\
\text { Order }\end{array}$ \\
\hline Package 1 & Yes & Most Preferred \\
\hline Package 10 & Abstain & Random \\
\hline Status Quo & Abstain & Random \\
\hline Package 11 & Abstain & Random \\
\hline Package 12 & Abstain & Random \\
\hline Package 13 & Abstain & Random \\
\hline
\end{tabular}

(b)
\begin{tabular}{|l|l|l|}
\hline $\begin{array}{l}\text { VRR Curve } \\
\text { (Ref. Fig. } 2)\end{array}$ & $\begin{array}{l}\text { Actual } \\
\text { Vote }\end{array}$ & Preference Order \\
\hline Package 1 & No & Least Preferred \\
\hline Package 10 & No & $5^{\text {th }}$ Most Preferred \\
\hline Status Quo & Abstain & Random \\
\hline Package 11 & Abstain & Random \\
\hline Package 12 & Abstain & Random \\
\hline Package 13 & Yes & Most Preferred \\
\hline
\end{tabular}

Examples of this procedure are shown in Table 4. Panel (a) shows an actual stakeholder who voted yes only to Package 1 and abstained for all the others. We assume that Package 1 is this voter's most preferred option, and randomly generate a preference order over the other five VRR curve options. Panel (b) shows an actual stakeholder who voted no to Packages 1 and 10, Yes to Package 13, and abstention to the rest. In this case, we assume that Packages 1 and 10 are the least preferred, while Package 13 is the most preferred. The preference order over the other voting options are randomly assigned.

For each stakeholder whose preferences fell into the abstention or inconsistent categories, we generated 1,000 realizations to complete the preference order.

\subsection{Simulating Capacity Market Rule Outcomes}

This section provides the results of our voting outcomes analysis. We model the stakeholder voting process to choose VRR curve parameters under the different voting mechanisms described in Section 2. Recall that when these VRR curve parameters were voted upon by PJM stakeholders, none of the proposed alternatives (including the alternative to make no changes to the VRR curve) were able to pass, and despite this PJM chose to file with FERC the VRR curve corresponding to Package 1. We will discuss three sets of results in this section. The first set of results discusses 
how imposing the NYISO voting structure onto PJM would change the outcome of the VRR curve voting process. The second set provides results of imposing a preferential voting system in PJM, but retaining the PJM passage threshold of $66.67 \%$. The third set of results layers the NYISO passage threshold of $58 \%$ onto the preferential voting analysis.

We first describe the results of imposing the NYISO passage threshold in the PJM stakeholder process. The modeled voting outcomes are shown in Table 5 . When we impose the NYISO sector-weighted voting structure onto the PJM stakeholder group, we make a few assumptions. We first assume that voters' decisions would not change under different threshold and sector weights. We also assume a straightforward translation of industry sectors in NYISO to those in PJM (see Table 2). For example, we assume voters in the Generation Owner sector of PJM corresponds to the Generation Owner sector in NYISO (which has a greater weight than PJM). We translate the Electric Distributor sector in PJM to the Public Power sector in NYISO as previously explained. After changing the threshold to $58 \%$ from $66.67 \%$ and the sector weights (see table 5), the results show that all proposals would fail except Package 13.

Table 5: VRR curve voting outcomes with the NYISO voting structure

\begin{tabular}{|l|l|l|l|l|l|l|}
\hline & $\begin{array}{l}\text { Status } \\
\text { Quo }\end{array}$ & $\begin{array}{l}\text { Package } \\
1\end{array}$ & $\begin{array}{l}\text { Package } \\
10\end{array}$ & $\begin{array}{l}\text { Package } \\
11\end{array}$ & $\begin{array}{l}\text { Package } \\
12\end{array}$ & $\begin{array}{l}\text { Package } \\
13\end{array}$ \\
\hline $\begin{array}{l}\text { Generation } \\
\text { Owner }\end{array}$ & 0.071 & 0.833 & 0.714 & 0.077 & 0.231 & 0.267 \\
\hline $\begin{array}{l}\text { Transmission } \\
\text { Owner }\end{array}$ & 0.083 & 0.8 & 0.75 & 0.167 & 0.167 & 0.333 \\
\hline Other Supplier & 0.056 & 0.667 & 0.323 & 0.235 & 0.25 & 0.513 \\
\hline $\begin{array}{l}\text { Electric } \\
\text { Distributor }\end{array}$ & 0.043 & 0 & 0 & 0.913 & 0.913 & 1 \\
\hline $\begin{array}{l}\text { End Use } \\
\text { Customer }\end{array}$ & 0.083 & 0 & 0 & 0.909 & 1 & 1 \\
\hline $\begin{array}{l}\text { Voting Score } \\
\text { and Result }\end{array}$ & 0.067 & 0.483 & 0.373 & 0.437 & 0.492 & 0.604 \\
\cline { 2 - 7 } & Failed & Failed & Failed & Failed & Failed & Pass \\
\hline
\end{tabular}

We next describe the results of our voting outcomes analysis under preferential voting. Because of the ambiguity of voter preferences in some cases and our Monte Carlo method of addressing this, we obtain distributions for voting outcomes rather than a single outcome (as in Table 5).

We first note that in all of our simulations, Package 13 was the chosen VRR curve alternative for the Instant Runoff Voting and Coombs models. When these voting systems are used in PJM, our model suggests a high level of robustness in the outcome regardless of any uncertainty over voter preferences.

The Borda Count voting model generated a greater variety of results, as shown in Table 6. In some cases, Package 11 or 12 was the winning alternative rather than
Package 13. More than $80 \%$ of the time, however, Package 13 was the winning alternative. This was true regardless of the level of the passage threshold.

Table 6: VRR voting outcomes under the Borda Count voting system, with the PJM and NYISO voting threshold (out of 1,000 simulations)

\begin{tabular}{|l|c|c|}
\hline & $\begin{array}{c}\text { PJM Threshold } \\
(66.7 \%)\end{array}$ & $\begin{array}{c}\text { NYISO Threshold } \\
(58 \%)\end{array}$ \\
\hline Package 11 & 2 & 42 \\
\hline Package 12 & 112 & 148 \\
\hline Package 13 & 886 & 810 \\
\hline
\end{tabular}

\section{Impacts of Voting Structures on Capacity Market Clearing}

As described in [2,4], PJM's current voting system has had difficulties in the passage of market rule changes in contentious issues such as capacity markets. In Section 4, we found that other voting procedures, such as a lower passage threshold or preferential voting would produce a passable voting proposal (we do not claim that the outcome produced would be good or bad for the system as a whole, only that the introduction of preferential voting or a lower passage threshould could lead to some outcome passing). We noted that the alternative voting structures that we considered would have the effect of reinforcing the political power held by consumer-side interests [2]. In this section we use the capacity market model developed in Section 3 to estimate the market impacts of the VRR curves that alternative voting structures may have passed.

As discussed in Section 5, IRV and Coombs choose package 13 and Borda count selects among package 11, 12 and 13 with probability of $4 \%, 15 \%$, and $81 \%$, respectively. Table 7 combines this information with the clearing price that our capacity market model suggests would emerge from each of the proposals. Modeled market clearing prices from these procedures are lower than the status quo outcome by around $\$ 2.92 / \mathrm{MW}$-day, and lower than the prices prevailing under Package 1 (which was selected by PJM after stakeholders failed to pass any of the alternatives) by $\$ 4.15 / \mathrm{MW}$-day.

Table 6: Sensitivity of capacity prices to voting structure

\begin{tabular}{|l|l|l|l|l|l|l|}
\hline \multicolumn{2}{|l|}{ Voting Procedures } & $\begin{array}{l}\text { Voting } \\
\text { Outcome }\end{array}$ & $\begin{array}{l}\text { Simulation } \\
\text { results* } \\
\text { PJM } \\
\text { (NYISO) }\end{array}$ & $\begin{array}{l}\text { Clearing Price } \\
\text { (\$/MW-day) }\end{array}$ & $\begin{array}{l}\text { \% changes in } \\
\text { Price compared } \\
\text { to Status quo }\end{array}$ & $\begin{array}{l}\text { \% changes in } \\
\text { Price compared } \\
\text { to Package 1 }\end{array}$ \\
\hline \multirow{3}{*}{$\begin{array}{l}\text { Preferential } \\
\text { voting }\end{array}$} & IRV & Package 13 & $100 \%$ & 125.93 & $-2.30 \%$ & $-3.61 \%$ \\
\cline { 2 - 7 } & Coombs & Package 13 & $100 \%$ & 125.93 & $-2.30 \%$ & $-3.61 \%$ \\
\cline { 2 - 7 } & Borda & Package 11 & $1 \%(4 \%)$ & 128.54 & $-0.28 \%$ & $-1.61 \%$ \\
\cline { 2 - 7 } & Package 12 & $11 \%(15 \%)$ & 126.42 & $-1.92 \%$ & $-3.23 \%$ \\
\cline { 2 - 7 } & Couckage 13 & $88 \%(81 \%)$ & 125.93 & $-2.30 \%$ & $-3.61 \%$ \\
\hline
\end{tabular}




\subsection{Sensitivity analysis}

This section repeats the capacity market analysis under two sensitivity analyses that could reasonably affect capacity prices. The first involves changing the Cost of New Entry (CONE), which acts as the price cap in the capacity market. The second involves changing the supply elasticity at the market-clearing point, making the supply curve steeper.

Figure 4 summarizes the sensitivity analysis for the level of the CONE. The $\mathrm{x}$-axis shows market clearing prices (\$/MW-day) and y-axis (left) represents the likelihood of observing the indicated clearing price or lower, based on our simulations. Dotted markers indicate outcomes from IRV or Coombs, and shaded markers display outcomes of Borda count. The shapes of the points represent the voting outcome given the voting procedure and the policy factor variation. Circle indicates package 13 as a voting result; square represents package 12; triangle represents package 11; diamond shape represents the status quo. Our result shows that policy variations do not change the probabilities of voting outcome (the right-hand y-axis) except one type of variation - increase in CONE value under Borda count. Due to increase in the CONE value, package 11's VRR curve becomes higher than that of the status quo VRR curve. In this case, the status quo VRR curve is the preferred outcome in a small number of our trials (4\%) instead of Package $11(0 \%)$ while the chances of Package $12(14 \%)$ and Package $13(82 \%)$ as a voting outcome remain identical. The picture also distinguishes variations in CONE values by setting different colors and line types to each variation. The blue solid line represents voting outcomes with the original CONE. Left of the blue line represents outcomes associated with lower CONE values and those to the right are associated with higher CONE values.

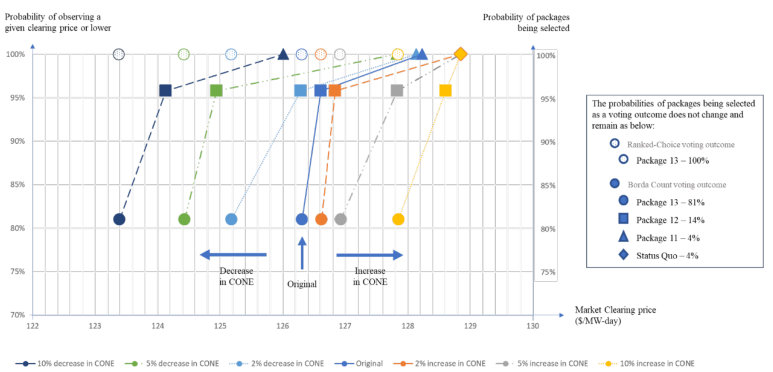

Figure 4: Sensitivity analysis on the level of the CONE.

Figure 4 illustrates that without any changes in the CONE value (original), under Borda count there is about 81 per cent chance that the clearing price would be around $\$ 126.25 / \mathrm{MW}$-day which is proposed by package 13; 96 per cent chance that the clearing price would be around $\$ 126.6 / \mathrm{MW}$-day or less, or 15 per cent incremental chance that the clearing price would be around $\$ 126.6 / \mathrm{MW}$-day which is suggested by package $12 ; 100$ per cent chance that the clearing price would be $\$ 128.2 / \mathrm{MW}$-day or less, or 4 per cent incremental chance that the clearing price would be $\$ 128.2 / \mathrm{MW}$-day that is what package 11 proposes. In comparison, under $\mathrm{RCV}$ with original policy factors, the clearing price would be $\$ 126.25 / \mathrm{MW}$-day by one hundred per cent chance.

We also perform a sensitivity analysis on the elasticity of supply at the market clearing point.. The price elasticities of supply range from 0.0656 to 0.1656 which shows that the supply in the capacity market is generally inelastic at the market clearing point. Since at the clearing price point the price elasticity of the supply is the lowest (0.0656), we mostly increase the elasticity to show market prices when other supplies that have higher price elasticity clear the market. Yet, we still consider a few cases in which more inelastic supply offer appear. To change the price elasticity of the supply at the clearing price point, we shift the supply curve at and to the right of the market clearing point (corresponding to shifting points 4, 5 and 6 in Figure 3 by identical percentages).

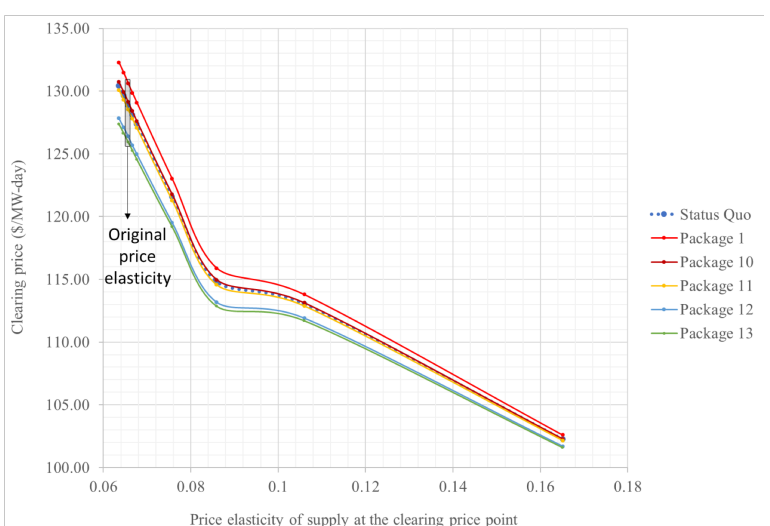

Figure 5: Sensitivity analysis on the elasticity of supply.

Figure 5 illustrates our sensitivity analysis of the supply price elasticity at the clearing price point. The curves in Figure 5 correspond to each proposed shape of the VRR curve. For each proposed VRR curve, Figure 5 shows how the clearing price would change under that VRR curve for various values of the supply elasticity. As the price elasticity increases, the difference between clearing prices of the status quo VRR curve and Package 13 tend to decrease. For example, with the original price elasticity of supply, 0.0656 , the clearing price of the package 13 is $\$ 125.93 / \mathrm{MW}$-day while that of the status 
quo is $\$ 128.90 / \mathrm{MW}$-day. If the elasticity increases to 0.0757 , the clearing price of Package 13 is $\$ 119.17 / \mathrm{MW}$-day and that of the status quo is $\$ 121.58 / \mathrm{MW}$-day. The difference has decreased from $\$ 2.97 / \mathrm{MW}$-day to $\$ 2.41 / \mathrm{MW}$-day and this difference is smaller when the elasticity is 0.1651 , the highest among our scenarios, which is $\$ 0.66 / \mathrm{MW}$-day. The result is consistent with a geometric interpretation of the supply and the VRR curve in Figure 2. From point $b$ to point $c$, the various VRR curves converge on one another as they meet at the point $c$. Therefore, as the supply curve is getting flatter, or as the price elasticity of the supply increases, the difference between clearing prices of the highest VRR curve and the lowest VRR curve would decrease.

\section{Conclusion and Future Work}

This study shows how the decision processes for establishing market rules in RTOs can materially affect market outcomes and investment incentives. We develop a modeling approach that can explicitly connect RTO rule-making decision systems with market outcomes, and illustrate it using a unique data set related to a series of capacity market votes.

Under PJM's current stakeholder voting structure, it can be difficult to reach an agreement that could be supported by two-thirds majority for divisive issues. We found that if PJM were to adopt alternative rules such as NYISO voting structure or preferential voting system, such a mechanism would more easily lead to passage of market rule changes for the capacity market. In the case that we studied, the outcome that would emerge favors the interests of consumers, producing lower capacity prices but also reducing PJM's installed capacity margin. Because of the structure of the stakeholder group in PJM, we believe that the political power enjoyed by consumer-side interests in our capacity market case study would extend to other issues, but we leave more detailed exploration as a matter for further research.

We do not claim that our modeled outcomes are better or worse than the actual outcomes that prevailed in the 2011 capacity market redesign exercise. Our analysis provides a framework for connecting RTO governance structures to market outcomes that can be used to evaluate the market or system impacts of governance decisions.

Our analysis provides evidence that voting rules can have a measurable impact on market outcomes which would affect two-thirds of the U.S. electricity consumption. While the magnitude of these market impacts are small in some cases, they are highly sensitive to other market and policy variables. We conclude that the impact of RTO governance structures on market outcomes is not negligible for capacity investment specifically. Whether this extends to other market products or elements of power grid operations is an avenue for potentially fruitful research.

This study also provides a good background to a comparison analysis across RTOs. Although we do not directly address difference in governance structures across RTOs and its consequences-except a passage threshold comparison with PJM and NYISO-the result that shows changes in voting outcomes under different voting rules is sufficient to further develop a research what these differences mean. We are not arguing that RTO governing rules have to be the same across different RTOs. All RTOs have developed their own rules over time based on countless debate and discussion that reflect distinct regional characteristics. However, we see few studies on comparing rule differences even though it could make non-negligible impact on the markets.

\section{Acknowledgements}

The authors acknowledge support from the U.S. National Science Foundation under award SES1261867, and the Alfred P. Sloan Foundation under award G-2019-12335.

\section{References}

[1] James, M., Jones, K. B., Krick, A. H., \& Greane, R. R. (2017). How the RTO stakeholder process affects market efficiency. https://www.ferc.gov/whatsnew/comm-meet/2008/101608/E-1.pdf.

[2] Blumsack, S., Yoo, K., \& Johnson, N. (2017). Can Capacity Markets Be Designed by Democracy? 50th Hawaii International Conference on System Sciences, Waikoloa, HI.

[3] Yoo, K., \& Blumsack, S. (2018a). The Political Complexity of Regional Electricity Policy Formation. Complexity, 2018, 1-18. doi:10.1155/2018/3493492

[4] Yoo, K., \& Blumsack, S. (2018b). Can capacity markets be designed by democracy? Journal of Regulatory Economics, 53(2), 127-151. doi:10.1007/s11149-0189354-1

[5] Dworkin, M. H., \& Goldwasser, A. (2007). Ensuring Consideration of the Public Interest in the Governance and Accountability of Regional Transmission Organizations. Energy Law Journal, 28, 543-601.

[6] Johnson, N., Yoo, K., Stafford, B., \& Blumsack, S. (2015). Of Social Structures and Infrastructure: Voting Networks in Regional Transmission Organizations. In Energy Policy Research Conference. Denver CO.

[7] Lenhart, S., Nelson-Marsh, N., Wilson, E. J., \& Solan, D. (2016). Electricity governance and the Western energy imbalance market in the United States: The necessity of interorganizational collaboration. Energy Research \& Social Science, 19, 94-107. doi:10.1016/J.ERSS.2016.05.015 
[8] Stafford, B. A., \& Wilson, E. J. (2016). Winds of change in energy systems: Policy implementation, technology deployment, and regional transmission organizations. Energy Research \& Social Science, 21, 222-236. doi:10.1016/J.ERSS.2016.08.001

[9] Simeone, C. (2017). PJM Governance: Can Reforms Improve Outcomes? http://kleinmanenergy.upenn.edu/sites/default/files/PJM Governance Reforms.pdf. Accessed 1 February 2018

[10] Carreras, B. A., Newman, D. E., Dobson, I., \& Zeidenberg, M. (2009). A simple model for the reliability of an infrastructure system controlled by agents. In Proceedings of the 42nd Annual Hawaii International Conference on System Sciences, Poipu HI.

[11] Arrow, K. J. (1950). A Difficulty in the Concept of Social Welfare. The Journal of Political Economy, 58(4), 328-346.

[12] Brams, S. J., \& Fishburn, P. C. (2002). Handbook of Social Choice and Welfare. Elsevier.

[13] Satterthwaite, M. A. (1975). Strategy-proofness and Arrow's conditions: Existence and correspondence theorems for voting procedures and social welfare functions. Journal of Economic Theory, 10(2), 187-217.

[14] Black, D. (1986). The Theory of Committees and Elections. Springer Netherlands.

[15] Endersby, J. W., \& Towle, M. J. (2014). Making wasted votes count: Turnout, transfers, and preferential voting in practice. Electoral Studies, 33, 144-152.

[16] Farrell, D. M., \& McAllister, I. (2006). Voter satisfaction and electoral systems: Does preferential voting in candidate-centred systems make a difference? European Journal of Political Research, 45(5), 723 749.

[17] Pfeifenberger, J. P., Newell, S. A., Spees, K., Murray, A., \& Karkatsouli, I. (2014). Third triennial review of PJM's variable resource requirement curve. Available online,

http://www.brattle.com/system/news/pdfs/000/000/658/ original/Third Triennial Review of PJM's Variable Resource Requirement Curve.pdf

[18] Bartholdi III, J. J., \& Orlin, J. B. (1991). Single transferable vote resists strategic voting. Social Choice and Welfare 8(4), 341-354.

[19] Horowitz, D. L. (1990). Making moderation pay: The comparative politics of ethnic conflict management.
Conflict and peacemaking in multiethnic societies, 451, 451-475.

[20] Kelly, J. S. (1988). Social Choice Theory : an Introduction.

[21] Edwards, G. S. (2015). Empowering Shareholders, Or Overburdening Companies - Analyzing the Potential Use of Instant Runoff Voting in Corporate Elections. Vanderbilt Law Review, 68.

[22] Borda, J. de. (1781). Mémoire sur les élections au scrutin. Available online, http://www.citeulike.org/group/1480/article/792703. Accessed 5 March 2018.

[23] Grofman, B., \& Feld, S. L. (2004). If you like the alternative vote (a.k.a. the instant runoff), then you ought to know about the Coombs rule. Electoral Studies, 23, 641-659.

[24] Dummett, M. (1998). The Borda count and agenda manipulation. Social Choice and Welfare, 15(2), 289296.

[25] PJM. (2012). Sensitivity Scenario Analysis Results. http://www.pjm.com/-/media/markets-ops/rpm/rpmauction-info/sensitivity-scenario-analysisresults.ashx?la=en

[26] Monitoring Analytics. (2015). Analysis of the 2015/2016 RPM Base Residual Auction. http://www.monitoringanalytics.com/reports/Reports/20 13/Analysis_of_2015_2016_RPM_Base_Residual_Auct ion_20130924.pdf. Accessed 9 February 2018

[27] Yoo, Kyungjin, 2019. Can the Grid Be Designed by Democracy? The Political Complexity of Regional Electricity Policy Formation, Ph.D. Dissertation, Pennsylvania State University.

[28] Arrow, K. J. (1950). "A difficulty in the concept of social welfare." The Journal of Political Economy: 328346.

[29] Rubinstein, A. (1980). "Stability of decision systems under majority rule." Journal of Economic Theory 23(2): 150-159.

[30] Epple, D., \& Riordan, M. H. (1987). Cooperation and punishment under repeated majority voting. Public Choice, 55(1-2), 41-73. 